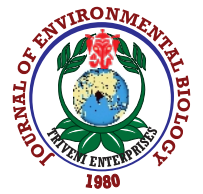

\title{
Mapping of active and empty aquaponds using spectral indices in coastal region of Guntur District, Andhra Pradesh, India
}

\author{
P. Prasuna Rani, M. Sunil Kumar and P.V. Geetha Sireesha \\ Geospatial Technology Centre, RARS, Acharya N.G. Ranga Agricultural University, Guntur-522 034, India \\ ${ }^{*}$ Corresponding Author Email : prasunaranip@gmail.com
}

\section{Abstract}

Aim: To evaluate spectral indices as tools for separation of active aquaponds filled with water and engaged in shrimp/fish production from empty aquaponds using Landsat -8 data in coastal region of Guntur district, Andhra Pradesh.

Methodology: The active and empty aquaponds were demarcated with Landsat satellite (Landsat-8) Operational Land Imager's (OLI) multispectral images using maximum likelihood classifier (MLC) algorithm and spectral indices like Normalized Difference Vegetation Index (NDVI), Normalized Difference Water Index (NDWI), Modified NDWI (MNDWI), Water Ratio Index (WRI) and Automated Water Extraction Index (AWEInsh) by means of thresholds.

Results: The supervised classification using maximum likelyhood classifier recorded the highest active aquapond area whereas; NDWI, combination of indices and WRI resulted in lower but almost similar extents. Evaluation of confusion matrix using validation points revealed that NDWI, WRI and combination of indices resulted in all most perfect agreement with a kappa value of more than 0.9. Maximum likelihood classifier, NDVI and MNDWI could separate active ponds and empty ponds from other land uses with strong agreement, while AWEInsh could separate different land uses only with moderate agreement.

Interpretation: The study indicates that spectral indices like NDWI, WRI and combination of indices are able to delineate aquaponds that were cultured for shrimp/fish and kept empty at a given time with noticeably high accuracy using satellite data for better managing of resources in coastal ecosystem

Key words: Aquaculture, Aquaponds, Decision trees, Spectral indices, Threshold values

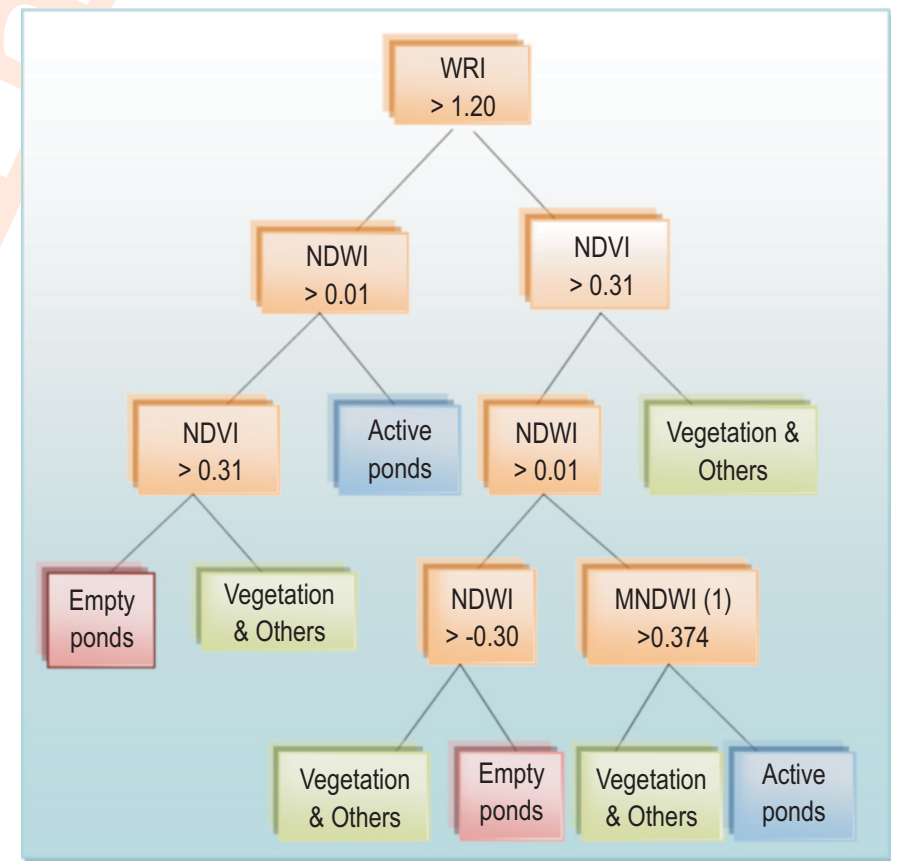

How to cite : Prasuna Rani P, Sunil Kumar M and Geetha Sireesha PV: Mapping of active and empty aquaponds using spectral indices in coastal region of Guntur District, Andhra Pradesh, India. J. Environ. Biol., 42, 1338-1346 (2021). 


\section{Introduction}

Globally, aquaculture is the fastest growing sector in food industry. Growing population and changing consumer preferences has resulted in an increased aquatic production. Andhra Pradesh has the second-longest coastline of $974 \mathrm{~km}$ among the states of India, after Gujarat. It is dominantly involved in shrimp production, with 70 per cent of the state itself. Much of the rice grown area in tail end regions of Krishna western delta has been brought under shrimp culture due to high profitability of aquaculture.

The geospatial tools viz., remote sensing and GIS are the crucial aids in resource inventory and monitoring. Detection and delineation of aquaculture areas can be done with their spectral response pattern as seen on the image or as portrayed in the changes in spectral radiance values of space-borne multispectral data (Dwivedi and Sreenivas, 2005). Operational Land Imager (OLI) is the latest optical sensor onboard Landsat 8 and is widely used for detecting surface water (Acharya et al., 2016; Singh et al., 2016; Yang et al., 2015). A number of water indices have been assessed for water extraction using Landsat OLI imagery according to the water conditions viz., clear water, turbid water (Xie et al., 2016). Previously, the aquapond regions were mapped by visual interpretation and digitization (Lokhande et al., 2017). The combined difference between NDVI and NDWI was found to enhance the contrast between water bodies and the surrounding surface features (Lu et al., 2011). The threshold values to extract water bodies may vary among varying conditions (Zhou et al., 2017). Water bodies are mapped using several water extraction algorithms like statistical pattern recognition techniques, including supervised grouping using ground information (Disperati and Virdis, 2015). The maximum likelihood classifier considers that the pixel values for each class in each band are normally distributed and computes the probability of a pixel belonging to a specific class (Jensen, 1996).

Spectral indices like Normalized Difference Vegetation Index (NDVI), Normalized Difference Water Index (NDWI), Modified NDWI (MNDWI), Water Ratio Index (WRI) and Automated Water Extraction Index (AWEInsh) combine two or more spectral bands using various algebraic operations to enhance the discrepancy between water bodies and land (Townshend and Justice, 1986). The normalized difference water index (NDWI), calculated using green and near-infrared bands (Green/NIR) reflectance, captured correct control points with an accuracy of greater than 95 percent (Liu et al., 2016). The individual indices or their combination are used for the estimation of surface water, by separating water from the background considering threshold values (Acharya et al., 2018, Hao, 2014). The threshold method is a quick and simple method, particularly when used with decision rules, for identification of water features. Alteration of the threshold value for water bodies can usually achieve better extraction results (Ji et al., 2009). Decision Tree classification (DTC) is also an effective and useful technique for classification of remote sensing data (Punia et al., 2011). Decision tree is a machine learning algorithm that allows grouping of an observation into categorical target variables by repeatedly dividing observations into mutually exclusive groups (Shailesh et al., 2014). A preliminary qualitative assessment shows that MLC and DTC exhibit similar distribution pattern of shallow water and fallow class but DTC map shows better results by differentiating various land-use parcels (Sharma et al., 2013).

Inland aquaculture, a common feature of coastal ecosystem, is highly vulnerable for vagaries of climate like cyclones, severe rains, heat waves, high humidity and associated pest outbreak. Onset of such unfavorable conditions may lead to crop failure. If such condition continues for two or more seasons, it causes financial setback to the farmers, particularly small and medium, forcing them to quit aquaculture.

Mapping of coastal aqua regions provide a baseline information and spatial distribution of active ponds and empty ponds. This would further help in monitoring coastal ecosystem, identifying the constraints, decision-making, and improve the socio-economic status of the aqua farmers. Keeping this in view, the present study was focused on mapping and acquiring up-todate spatial information regarding distribution of coastal aquaculture in Guntur district, Andhra Pradesh using remote sensing and GIS.

\section{Materials and Methods}

In this study, the coastal region of Guntur district, dominated by brackish aquaculture, was selected as study area. A region of interest was identified mainly covering major aquapond regions of Guntur district, Andhra Pradesh, India (Fig.1). The mapping of aquapond regions of Guntur district was carried out as depicted in Fig. 2.

Landsat $8 \mathrm{OLI}$ image courtesy of the U.S. Geological Survey bearing path 142 and row 49 acquired on $15^{\text {th }}$ March 2019 with a cloud cover of 0.11 per cent was downloaded (Courtesy United States Geological Survey) and radiometric correction was carried out to reduce the haze in the data. The colour composite of area of interest was extracted for further processing.

The processed data were interpreted visually considering the image elements like pattern, tone, shape, association etc., to identify the locations for ground truth collection for active aquaponds, empty ponds and vegetation and other features related to the study. Considering the remote sensing data with different band combinations, ground truth observations, high resolution Google maps and expert knowledge, the land use classification of the study area was carried out.

A training set was developed using the signatures of the features based on ground truth observations. Automatic 


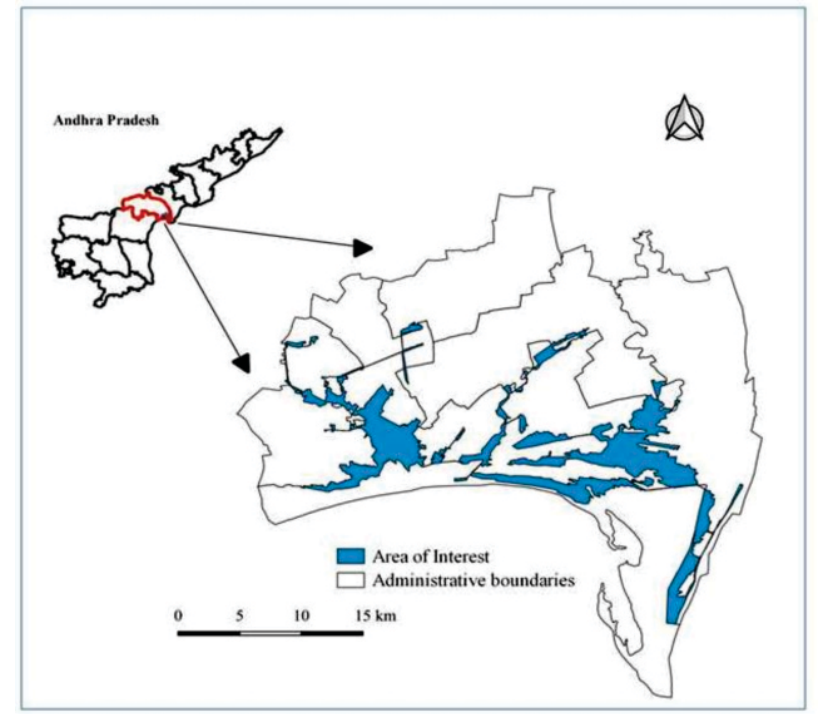

Fig. 1 : Study area located in Guntur district, Andhra Pradesh.

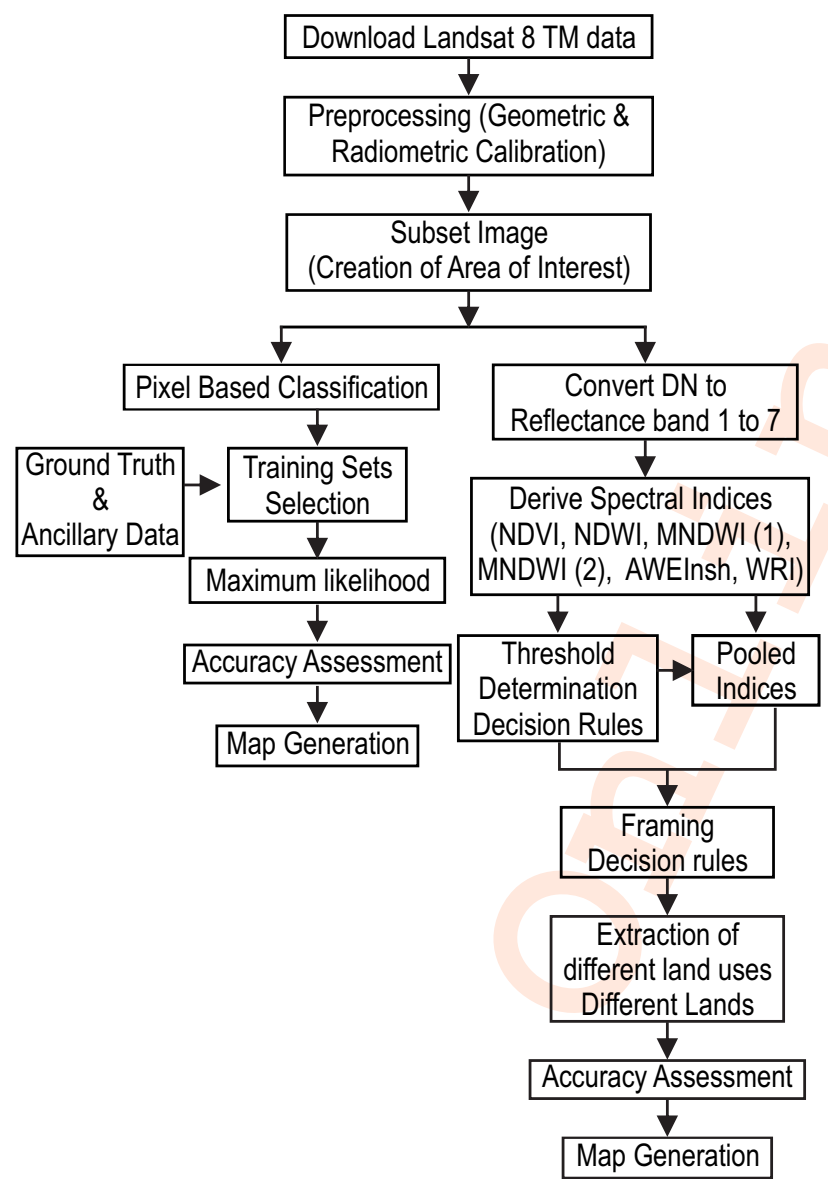

Fig. 2 : Methodology adopted for the study.

classification of the study area was carried out using maximum likelihood classifier in ERDAS imagine 2018. However, to arrive at better classification products, spectral indices were used for classification studies. The Landsat 8 OLI data containing information as digital numbers were converted to top of atmosphere reflectance using the rescaling coefficients in the MTL file of the downloaded image as follows with a spatial modeler in ERDAS Imagine following the procedure given by USGS for Landsat Level-1 Data Product. (https://www.usgs.gov/ land-resources/nli/landsat/using-usgs-landsat-level-1-dataproduct)

$$
\rho \lambda^{\prime}=M \rho Q c a l+A \rho
$$

Where, $\rho \lambda$ ' is the TOA planetary reflectance, without correction for solar angle; $\mathrm{M} \rho$ is the Band-specific multiplicative rescaling factor from the metadata (REFLECTANCE_MULT_BAND_x, where $\mathrm{x}$ is the band number); $A \rho$ is the Band-specific additive rescaling factor from the metadata (REFLECTANCE_ADD_BAND_x, where $x$ is the band number); $Q_{\text {cal }}$ is the Quantized and calibrated standard product pixel values (DN) TOA reflectance with a correction for the sun angle was calculated by the formula :

$$
\rho \Lambda=\rho \lambda^{\prime} / \cos \left(\theta_{\text {SZ }}\right)=\rho \lambda^{\prime} / \sin \left(\theta_{\text {SE }}\right)
$$

Where, $\rho \lambda$ is the TOA planetary reflectance; $\theta_{\mathrm{SE}}$ is the Local sun elevation angle. The scene center sun elevation angle in degrees is provided in the metadata (SUN_ELEVATION); $\theta_{\mathrm{Sz}}$ is the Local solar zenith angle; $\theta_{\mathrm{Sz}}=90^{\circ}-\theta_{\mathrm{SE}}$

The reflectance was calculated for all the bands and the reflectance bands of blue, green, red, INR, SWIR1 and SWIR2 were overlaid to produce a composite for further use.

Various spectral indices were used to map the active aquaponds, empty ponds and vegetation and other land uses. The Normalized Difference Vegetation Index (NDVI) and Normalized Difference Water Index (NDWI) were derived from the ratio of difference between reflectance of NIR and Red to total of NIR and Red bands (Kriegler et al., 1969) and difference between reflectance of Green and NIR to total of Green and NIR bands (McFeeters, 1996), respectively. The Automated Water Extraction Index (AWEInsh is considered as shadows are not a problem) was estimated from the reflectance of Green and SWIR 1 bands as given by Feysia et al. (2014). The ratio of total reflectance of Green and Red bands to that of NIR and SWIR 1 was used to derive Water Ratio Index (WRI) (Shen and Li, 2010). The reflectance of SWIR 1 and SWIR 2 bands was used along with Green brand to derive Modified Normalized Difference Water Indices viz., MNDWI(1) and MNDWI(2), respectively $(\mathrm{Xu}, 2006)$

Since, the objective of the study was to determine the active aquaponds, empty aquaponds and vegetation and other land uses in the area of interest, the threshold approach was considered. Thresholds for various indices were decided using 170 validation points covering all three land use classes. The reflectance characters of the interested features in different 


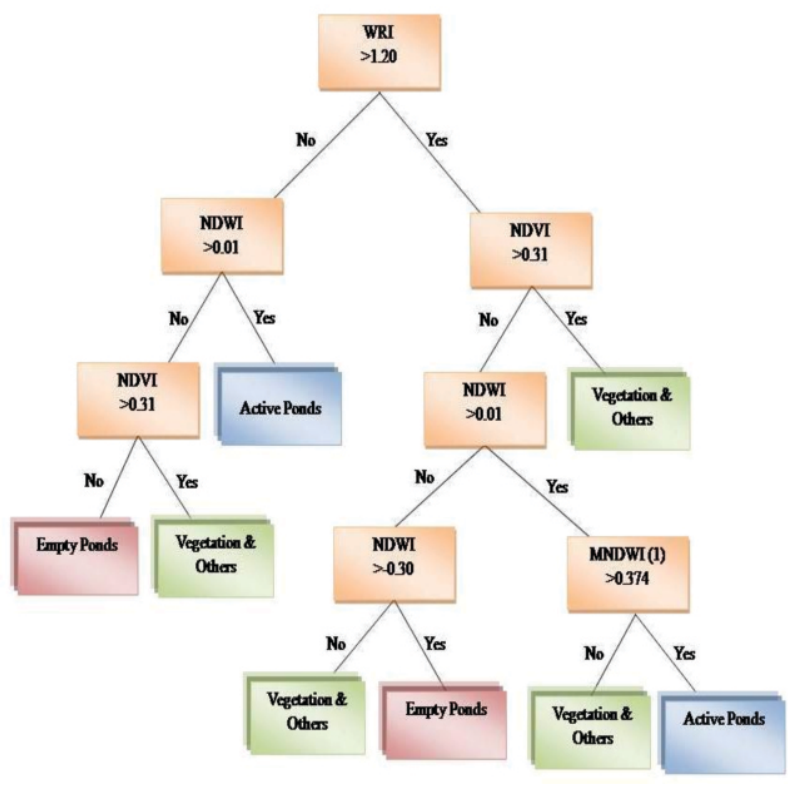

Fig. 3 : Decision tree built using multiple indices for delineation.

bands of multiband composite of Landsat data, ground truth information, Google earth maps and input from local experts formed a basis for finalizing thresholds for various indices (Table $1)$.

Decision rules were framed using the thresholds prescribed above to separate the land classes for each index in ENVI software. Then the indices, which could better discriminate the classes, were considered to construct a combined decision tree (Fig. 3).
Once the threshold based decision rule grouping of the study area into active aquaponds, empty ponds and other uses was performed, the accuracy assessment using Cohen's kappa coefficient ( $\mathrm{K}$ ) (Cohen, 1960) was carried out. It is a statistic used to measure inter-rater reliability and intra-rater reliability for qualitative (categorical) items. It takes into account the possibility of agreement occurring by chance. The confusion matrix was carried out manually to find the producer accuracy, consumer accuracy, overall accuracy and kappa index (KI) to identify the best means to classify automatically.

\section{Results and Discussion}

The highest active pond area of 4552 ha and the lowest empty pond area of 4390 ha was extracted with supervised classification following maximum likelihood algorithm (Table 2). It was observed that many of the active ponds were grouped into empty ponds and vice versa as the reflectance values of the ponds varied highly depending on the depth of water, age of the active ponds, algal growth etc. Such factors lead to misclassification of land use classes. Supervised classification could not reach higher accuracy values, as the requirement for purity of classification was rather high (Yang et al., 2011). Various spectral indices like NDVI, NDWI, AWEInsh and WRI and Combined index grouping were found useful in differentiating area of interest into three classes viz., active ponds, empty ponds and vegetation and others by establishing optimum thresholds (Fig. 4). While, MNDWI calculated using SWIR1 or SWIR 2 could be used to differentiate only active ponds from others. Overlapping of reflectance values for empty ponds and vegetation and others limited the establishment of two thresholds for separation of land use into three classes using MNDWI.

Table 1: Threshold values of various land uses for spectral indices used in decision trees

\begin{tabular}{llll}
\hline Index & Active aquaponds & Empty aquaponds & Vegetation and others \\
\hline NDVI & $<0.032$ & 0.032 to 0.310 & $>0.31$ \\
NDWI & $>0.010$ & 0.010 to -0.300 & $>-0.3$ \\
AWEInsh & $>0.265$ & 0.009 to 0.265 & $<0.009$ \\
WRI & $>1.2$ & 1.2 to 0.6 & $<0.6$ \\
MNDWI & $>0.189$ & No class & $<=0.1890$ \\
MNDWI $(1)$ & $>0.374$ & No class & $<=0.3739$ \\
\hline
\end{tabular}

Table 2 : Extent (ha) of different land uses estimated using spectral indices.

\begin{tabular}{llll}
\hline Index/Class & Active aquaponds & Empty aquaponds & Others \\
\hline Maximum likelihood classifier & 4552 & 4390 & 1203 \\
NDVI & 3345 & 5599 & 1201 \\
NDWI & 3398 & 5693 & 1054 \\
AWEInsh & 3076 & 6107 & 962 \\
WRI & 3559 & 5256 & 1330 \\
Combination of indices & 3373 & 5059 & 1713 \\
MNDWI1 & 4169 & Not considered & 5975 \\
MNDWI2 & 4211 & Not considered & 5934 \\
\hline
\end{tabular}




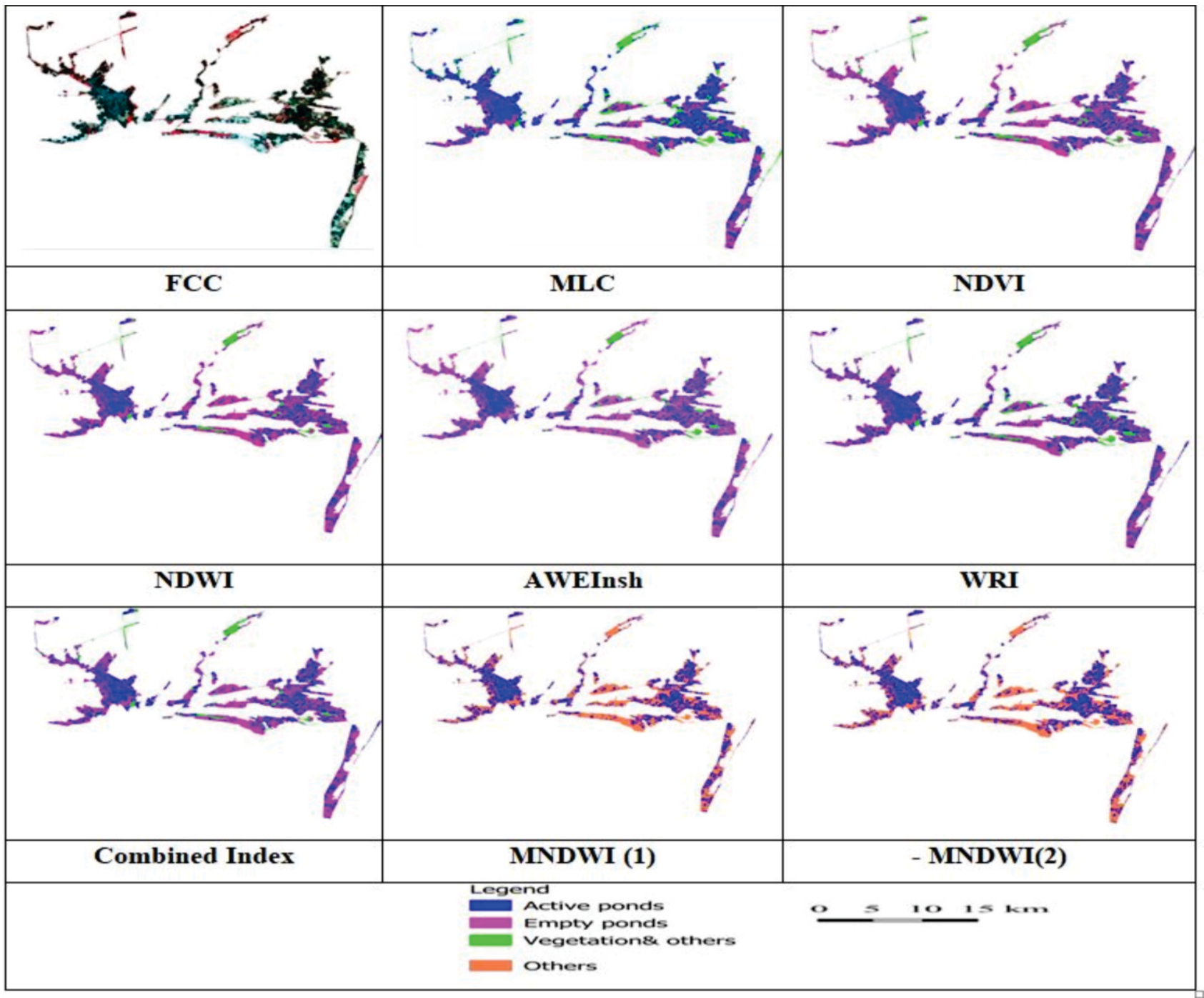

Fig. 4 : Maximum likelihood and Index based classification of aquapond region.

However, MNDWI gives more detailed information regarding open water than does the NDWI (Gulcan and Mehmet Ozcelik, 2017). Decision rules were framed using the thresholds prescribed earlier to separate the land classes for each index. The indices which could discriminate the classes with reasonably high accuracy were used to construct a combined decision tree in ENVI software for better separation of active and empty ponds (Table 3).

The NDVI, NDWI and Combination of indices resulted in similar extent of active ponds, with a variation of about 100 ha, while, variation in other uses was high. The NDVI has a low level of free water detection, often confusing bare soils with free water. Misinterpretation of turbid water bodies as bare soils with NDVI was observed by Valerie Soti et al. (2009). NDWI was good at eliminating the shadows but weak in extracting small water bodies (Gao et al., 2016). However, Ahmed and Akter (2017) found that NDVI and NDWI were prominent to identify vegetation and water covers. The fallow areas class was best identified with NDWI and NDVI indices; NDWI was also the best performing index to determine the constructed areas and water bodies (Vanessa et al., 2020)

Combination of indices like WRI, NDWI, NDVI and MNDWI (1) with threshold based decision rules performed the best in separating different land uses. It could even separate the bunds also, which were mostly considered under empty ponds with NDVI and NDWI. The NDWI alone failed to detect many smaller, more turbid water bodies while the Gond's decision tree method using NDWI, NDVI and SWIR1 detected water bodies with maximum overall accuracy of 0.96 (Kelsey et al., 2020). The threshold values prescribed for AWEInsh resulted in the lowest extent of active ponds and a maximum of empty ponds compared to the remaining indices tested. In the present study, many of the 


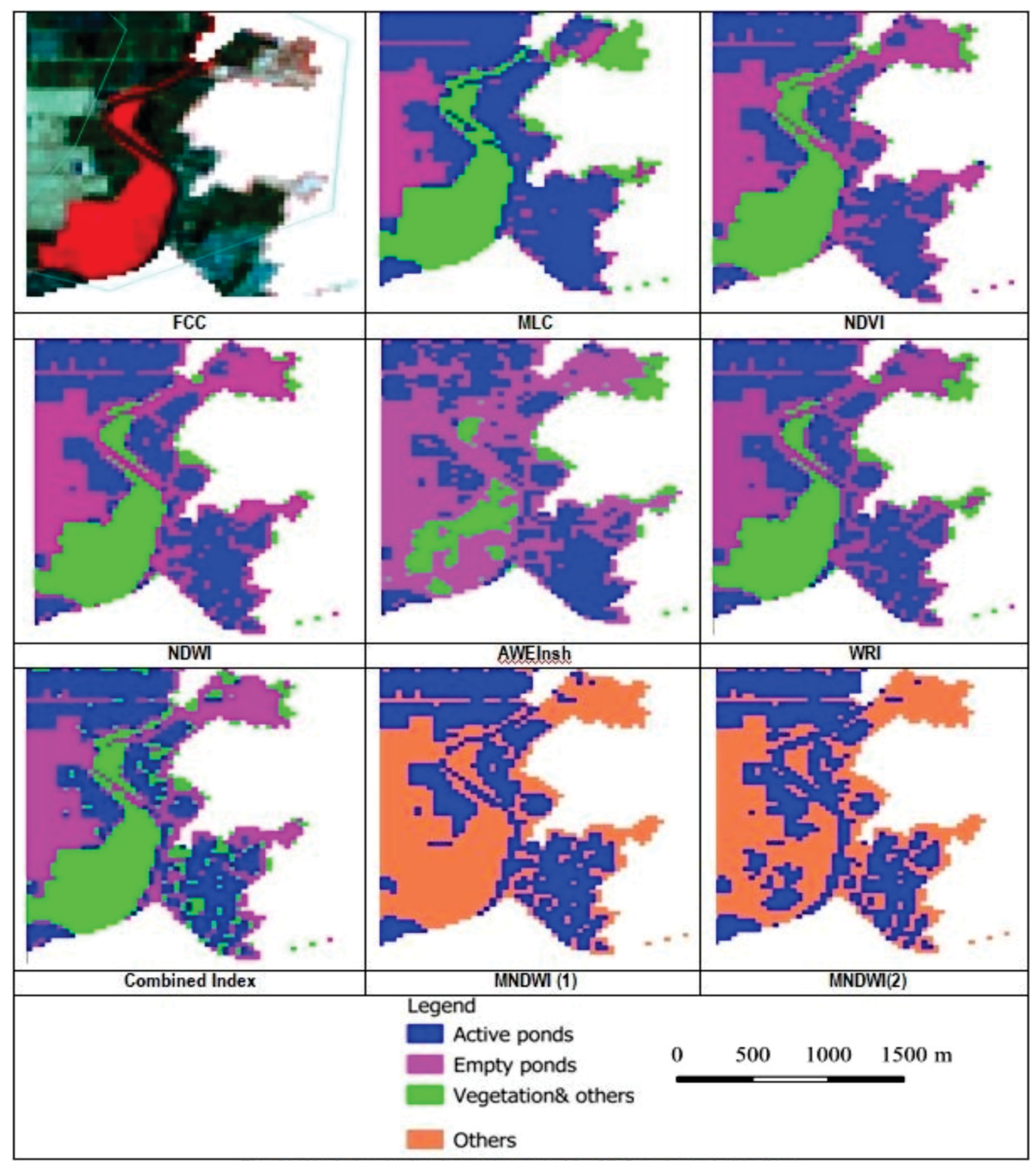

Fig. 4 (a) : Variation in land uses extracted by MLC and spectral indices.

areas in other land uses including marshy lands were grouped into empty ponds (Fig. 4a and 4b). The AWEInsh was most likely to confuse mixed water pixels, followed by MNDWI, and NDWI (Hao et al., 2014) and that might be the reason for misclassification. Similarly, Ying et al. (2018) could not identify small linear rivers using AWEInsh due to false extraction of back ground objects outside the river area.

WRI, which considers the ratio of sum of reflectance of visible region (green and red) to the sum of NIR and SWIR (1) was 


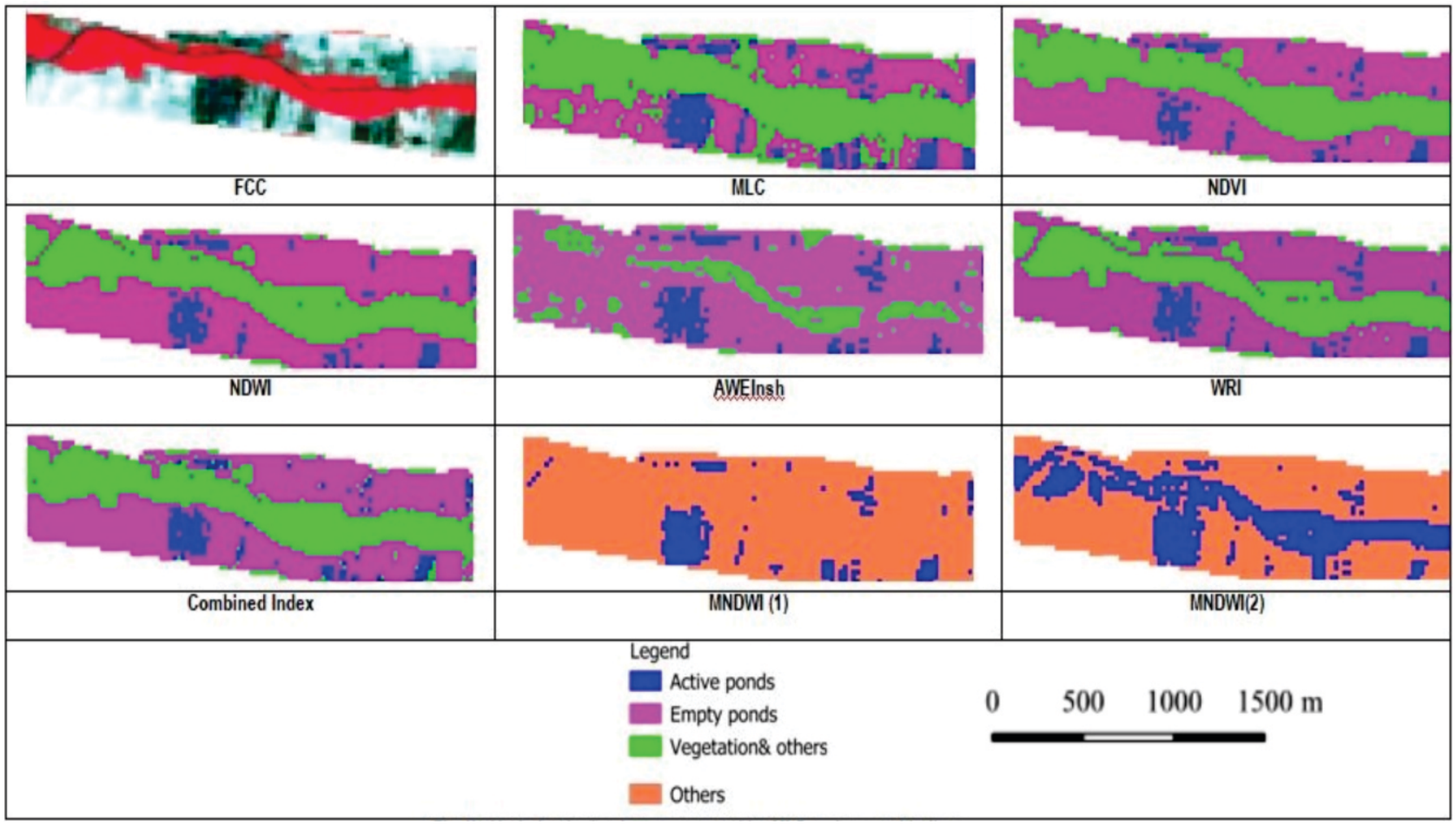

Fig. 4 (b) : Variation in land uses extracted by MLC and spectral indices.

Table 3 : Accuracy assessment of aquaponds using different spectral indices

\begin{tabular}{|c|c|c|c|c|c|}
\hline Index/Class & Land use & PA & UA & $O A$ & ki \\
\hline \multirow[t]{3}{*}{ Maximum likelihood classifier } & Active ponds & 93.18 & 92.00 & \multirow[t]{3}{*}{0.88} & \multirow[t]{3}{*}{0.82} \\
\hline & Empty ponds & 72.22 & 92.86 & & \\
\hline & Vegetation \&others & 93.18 & 78.85 & & \\
\hline \multirow[t]{3}{*}{ NDVI } & Active ponds & 0.98 & 0.95 & \multirow[t]{3}{*}{0.93} & \multirow[t]{3}{*}{0.89} \\
\hline & Empty ponds & 0.93 & 0.94 & & \\
\hline & Vegetation \&others & 0.97 & 0.92 & & \\
\hline \multirow[t]{3}{*}{ NDWI } & Active ponds & 0.91 & 1.00 & \multirow[t]{3}{*}{0.95} & \multirow[t]{3}{*}{0.92} \\
\hline & Empty ponds & 0.98 & 0.94 & & \\
\hline & Vegetation \&others & 0.97 & 0.89 & & \\
\hline \multirow[t]{3}{*}{ AWEInsh } & Active ponds & 0.91 & 0.89 & \multirow[t]{3}{*}{0.82} & \multirow[t]{3}{*}{0.72} \\
\hline & Emptyponds & 0.75 & 0.83 & & \\
\hline & Vegetation \&others & 0.80 & 0.68 & & \\
\hline \multirow[t]{3}{*}{ WRI } & Active ponds & 0.97 & 0.97 & \multirow[t]{3}{*}{0.97} & \multirow[t]{3}{*}{0.95} \\
\hline & Emptyponds & 0.96 & 0.99 & & \\
\hline & Vegetation \&others & 1.00 & 0.95 & & \\
\hline \multirow[t]{3}{*}{ Combined index } & Active ponds & 0.92 & 0.98 & \multirow[t]{3}{*}{0.99} & \multirow[t]{3}{*}{0.98} \\
\hline & Empty ponds & 1.00 & 1.00 & & \\
\hline & Vegetation \&others & 0.97 & 1.00 & & \\
\hline \multirow[t]{2}{*}{ MNDWI(1) } & Active ponds & 0.84 & 1.00 & \multirow[t]{2}{*}{0.93} & \multirow[t]{2}{*}{0.86} \\
\hline & Others & 1.00 & 88.89 & & \\
\hline \multirow[t]{2}{*}{ MNDWI(2) } & Active ponds & 0.88 & 1.00 & \multirow[t]{2}{*}{0.95} & \multirow[t]{2}{*}{0.90} \\
\hline & Others & 1.00 & 0.92 & & \\
\hline
\end{tabular}

found to extract slightly higher active ponds and other uses but relatively lower extent of empty ponds to that of NDWI/NDVI/ Combined index based classification.
MNDWI calculated using either SWIR1 or SWIR 2 has recorded relatively higher active pond area compared to the remaining indices. MNDWI was found to separate aquaponds 
from others using threshold values but empty ponds could not be separated from vegetation and others. The ponds, which were drained recently or wet due to seepage water from surrounding ponds could not be discriminated by MNDWI thereby, classed into active ponds. In contradictory, Kanwar et al. (2015) proposed that MNDWI values were positive for water features mixed with vegetation and could be used to better delineate water features compared to NDWI.

Image classification accuracy was characterized by confusion matrix (or error matrix), which shows relation between the classification result and a reference. Overall accuracy was calculated by the ratio of sum of number of correctly identified pixels to that of total number of pixels. The mismatch of the reference and the classified image resulted in underestimation (omission errors) or overestimation (commission errors). Errors of commission occur when a classification procedure assigns pixels to a certain classes that in fact do not belong to it. Sum of these pixels mistakenly assigned to a class was divided by the total number pixels of that class to arrive at relative commission error, which, when deducted from one (1.0) resulted in Producer accuracy. Similarly, when pixels that in fact belong to one class were included into other classes, resulted in Error of omission. The sum of omitted pixels was divided by the total number of class pixels, to arrive at omission error from which User accuracy was calculated by subtracting it from one.

The details of accuracy assessment using confusion matrix (Table 3 ) helped in arriving at the best index for differentiating various land uses in the study area. The highest overall accuracy as well as kappa index for combination of indices based classification indicated the best reliable area estimates for the interested land uses in the study area. All most similar accuracy levels were recorded for WRI followed by NDWI and NDVI. The boundaries of different reservoirs were extracted by Hui Yue et al. (2020) with kappa values of 0.9869 and 0.9855 for NDWI and MNDWI, respectively.

Maximum user accuracy of one for active ponds with NDWI indicated no omission of water filled ponds in the classification. Similarly, the maximum of one recorded for producer accuracy with different indices for different classes indicated that no other classes were grouped into that class. The indices with more than 0.9 kappa index viz., Combination of indices, WRI and NDWI were found to classify the data with almost perfect matching between the classified image and reference. The NDVI and maximum likelihood classifier have kappa index between 0.8 and 0.9 , and could differentiate all three classes with strong matching, while MNDWI with similar KI could be used for separating active ponds from other uses. AWEInsh differentiated three classes with only moderate matching ( 0.60 to $0.70)$ due to misclassification of vegetation and others classes, particularly the marshy areas into empty ponds (Fig.4a, b). MNDWI calculated with SWIR1 resulted in relatively higher producer and consumer accuracy than SWIR2.

Location specific thresholds fixed for various indices arrived using random points were found to group the study area into active ponds, empty ponds and other uses. Accuracy assessment using validation points revealed that NDWI, WRI and Combination of indices are useful to delineate and map seasonal variations in the aquaponds actually used for shrimp/ fish culture.

\section{Add-on Information}

Author's contribution : P. Prasuna Rani: Planning, Data processing and analysis, Final product generation; M. Sunil Kumar: Ground survey and collection of information in a specific proforma; P.V. Geetha Sireesha: Validation of data.

Research content : The research content is original and has been not published elsewhere.

\section{Ethical approval : Not applicable}

Conflict of interest : The authors declare that there is no conflict of interest.

Data from other sources : USGS earth explorer.

Consent to publish : All authors agree to publish the paper in Journal of Environmental Biology.

\section{References}

Acharya, T.D., D.H. Lee, I.T. Yang and J.K. Lee: Identification of water bodies in a Landsat $8 \mathrm{OLI}$ image using a J48 decision tree. Sensors, 16,1075 (2016).

Acharya, T.D., A. Subedi and D.H. Lee: Evaluation of water indices for surface water extraction in a Landsat 8 Scene of Nepal. Sensors, 18,2580 (2018).

Ahmed, K.R. and S. Akter: Analysis of landcover change in southwest Bengal delta due to floods by NDVI, NDWI and K-means cluster with landsat multi-spectral surface reflectance satellite data. Remote Sen. Applic. Soci. Environ., 8, 168-181 (2017).

Cohen, J.A.: Coefficient of agreement for nominal scales. Educ. Psychol. Meas, 20,37-46 (1960).

Disperati, L. and S.G.P. Virdis: Assessment of land-use and land-cover changes from 1965 to 2014 in Tam giang-cau Hai lagoon, Central Vietnam. Appl. Geogr., 58, 48-64 (2015).

Dwivedi, R.S. and K. Sreenivas: Delineation and monitoring of aquaculture areas using multi-temporal space-borne multispectral data. Curr. Sci., 89, 1414-1420 (2005).

Feysia, G.L., H. Meilby, R. Fensholt and S.R. Proud: Automated water extraction index: Anew technique for surface water mapping using Landsat imagery. Remote Sens. Environ., 140, 23-35 (2014).

Gao, H., L. Wang, L. Jing and J. Xu: An effective modified water extraction method for Landsat-8 OLI imagery of mountainous plateau regions. 9th Symposium of the International Society for Digital Earth (ISDE). Earth Environ. Sci., 34, 012010 (2016). 
Gulcan, S. and M. Ozcelik: Water body extraction and change detection using time series: A case study of Lake Burdur, Turkey. J. Taibah Univ. Sci., 11, 381-391 (2017).

Hao, J., M. Feng, Y. Zhu, N. Lu, J. Huang and T. Xiao: An automated method for extracting rivers and lakes from Landsat Imagery. Remote Sens., 6, 5067-5089 (2014).

Hui, Y., Y. Li, J. Qian and Y. Liu: A new accuracy evaluation method for water body extraction. Int. J. Rem. Sen., 41,1-32 (2020)

Jensen, J.R.: Introductory Digital Image Processing A Remote Sensing Perspective. $2^{\text {nd }}$ Edn., Prentice Hall, Inc., Upper Saddle River, NJ, pp. 225-230 (1996).

Ji, L., L. Zhang and B. Wylie: Analysis of dynamic thresholds for the normalized difference water index. Photogramm. Engin. Rem. Sen., 75, 1307-1317 (2009).

Kanwar, V.S., R. Setia, S. Sahoo, A. Prasad and B. Pateriya: Evaluation of NDWI and MNDWI for assessment of waterlogging by integrating digital elevation model and groundwater level. Geocarto Int., 30, (2015). DOI: 10.1080/10106049. 2014.965757.

Kelsey, H., R. Muench, E. Cherrington and R. Griffin: An assessment of surface water detection methods for water resource management in the Nigerien Sahel. Sensors, 20, 431 (2020).

Kriegler, F.J., W.A. Malila, R.F. Nalepka and W. Richardson: Preprocessing transformations and their effect on multispectral recognition. In: Proceedings of the sixth International Symposium on Remote Sensing of Environment, University of Michigan, Ann Arbor, Ml, pp. 97-131 (1969).

Landsat 8 (L8) Data Users Handbook, Version 5.0 pp 54-55 U.S. Geological Survey (2019).

Liu, Z., Z. Yao and R. Wang: Assessing methods of identifying open water bodies using Landsat 8 OLI imagery. Environ. Earth Sci., 75, 1-13 (2016).

Lokhande, P.C., M.M. Shirdhankar, K.C. Chaudhari and M.S. Sawant: Digitization of inland water resources for fisheries through remote sensing and geographical information system - Astudy in Ratnagiri District. Fishery Technology, 54, 86-93 (2017).

Lu, S., B. Wu, N. Yan and Yan and H. Wang: Water body mapping method with HJ-1A/B satellite imagery. Int. J. Appl. Earth Obs. Geoinf., 13, 428-434 (2011).

McFeeters, S.K.: The use of normalized difference water index (NDWI) in the delineation of open water features. Int. J. Remote Sens., 17,1425-1432 (1996).

Punia, M., P.K. Joshi and M.C. Porwal: Decision tree classification of land use land cover for Delhi, India using IRS-P6 AWiFS data. Exp. Syst. Applicat., 5, 5577-5583 (2011).
Shailesh, J., R. Anil and G. Sanjeev: Decision tree approach to build a model for water quality. Binary J. Data Min. Networ., 4, 25-28 (2014).

Sharma, R., A. Ghosh and P. Joshi: Decision tree approach for classification of remotely sensed satellite data using open source support. J. Earth Sys. Sci., 122, 1237-1247 (2013).

Shen, L. and C. Li: Water body extraction from Landsat ETM+ imagery using adaboost algorithm; Proceedings of the $18^{\text {th }}$ International Conference on Geoinformatics, IEEE, pp. 1-4 (2010).

Singh, K., M. Ghosh and S.R. Sharma: WSB DA: Water surface boundary detection algorithm using Landsat 8 OLI data. IEEE $J$. Sele. Top. App. Eth. Obser. Rem. Sen., 9, 363-368 (2016).

Townshend, J.R. and C. Justice: Analysis of the dynamics of African vegetation using the normalized difference vegetation index. Int. J. Remote Sens, 7, 1435-1445(1986).

Valerie, S., A. Tran, S.B. Jean, P. Christian, L.S. Danny and B. Agnes: Assesing optical earth observation system for mapping and monitoring temporary ponds in arid areas. Inter. J. App. Earth Obser. Geoinfor., 11, 344-351(2009).

Vanessa, S. S., G. Salamia, M.I.O. da Silva, E.A. Silva, J.J.M. Junior and E. Alba: Methodological evaluation of vegetation indexes in land use and land cover (LULC) classification. Geol. Ecol. Landsc., 4, 159-169 (2020).

Xie, H., X. Luo, X. Xu, H. Pan and X. Tong: Evaluation of Landsat 8 OLI imagery for unsupervised inland water extraction. Int. J. Rem. Sen., 37, 1826-1844 (2016).

$\mathrm{Xu}, \mathrm{H}$.: Modification of normalised difference water index (NDWI) to enhance open water features in remotely sensed imagery. Int. J. Rem. Sens., 27, 3025-3033 (2006).

Yang, H., W. Zongmin, Z. Hongling and G. Yu: Water body extraction methods study based on RS and GIS. Proc. Environ. Sci., 10, 2619 -2624 (2011).

Yang, Y., Y. Liu, M. Zhou, S. Zhang, W. Zhan, C. Sun and Y. Duan: Landsat $8 \mathrm{OLI}$ image based terrestrial water extraction from heterogeneous backgrounds using a reflectance homogenization approach. Rem. Sens. Environ., 171, 14-32 (2015).

Ying, Z., H. Zhao, H. Han and C. Wang: A new multispectral threshold normalized difference water index (MST-NDWI) water extraction method - A case study in Yanhe. The International Archives of the Photogrammetry, Remote Sensing and Spatial Information Sciences, 42, 2557-2564 (2018).

Zhou, Y., J. Dong, X. Xiao, T. Xiao, Z. Yang, G. Zhao, Z. Zou and Y. Qin: Open surface water mapping algorithms: A comparison of waterrelated spectral indices and sensors. Water, 9, 256 (2017). 